\title{
THE OVERVIEW OF SPACE APPLICATIONS FOR ENVIRONMENT INITIATIVES
}

\author{
Shin-ichi Sobue*1, Toru Fukuda*1, Toshio Koike*2, Wataru Takeuchi*3, Tsugito Nagano*1 and Tomoyuki Nukui*1 \\ *1 JAXA, Earth observation research center, 2-1-1 Sengen, Tsukuba, Ibaraki 305-8505, Japan, sobue.shinichi@jaxa.jp \\ *2 School of Engineering, The University of Tokyo, Bunkyo-ku, Tokyo 113-8656, Japan \\ *3 IIS, The University of Tokyo, Komaba, Meguro 153-8505, Japan
}

\section{Commission VIII, JAXA Special Session}

Keyword: environment, satellite

\begin{abstract}
Recently, climate change and human activities accelerate hazards, such as deforestations, land slides, draughts, floods in AsianPacific countries are increased. To mitigate the hazards due to climate change and human activities, environmental monitoring has become important. Monitoring of the condition of Land, Air, Ocean, and Water Resources (LAOWR ) by using space based technology are very important. To determine the threshold between normal and abnormal is important and the threshold itself could change with climate change and human activities. Asian Pacific regional forum (APRSAF) agreed to host SAFE (Space Applications For Environment) initiatives. Under APRSAF, there are on-going several SAFE prototyping for water management and forest monitoring This paper describes SAFE overview and current situation of SAFE prototyping.
\end{abstract}

\section{INTRODUCTION}

SAFE is a voluntary-based initiative. It aims to encourage the environmental monitoring in long-term to grasp the environmental changes that may be useful to bring in risk reduction and adaptation programs for disasters risk related activities to other climate change associated problems using space applications, especially satellite remote sensing technology. Some of the changing environment parameters in water resources, river water level, land cover, deforestation, agricultural production, and ecosystem could provide through satellite remote sensing.

SAFE considers continuous data provision with sensor data that could provide environment sensitive information with varying spectral and spatial resolution for better understanding the status of the environment and its changes. SAFE is a more robust approach for long-term monitoring of our natural environment with satellite remote sensing to evaluate current status, understand the changes, monitor the nature of changes and where possible use as base information for risk management and adaptation. Further, the end users of SAFE are the agencies and experts work on various agencies that are responsible for the environment. These agencies have their own mandate, functionalities and responsibilities to sustainable management of the environment.

\section{SAFE OVERVIEW}

\subsection{Background}

Climate change and Human activities accelerate hazards, such as deforestations, landslides, droughts, floods in Asian-Pacific countries. To mitigate the hazards due to climate change and human activities, environmental monitoring has become more and more important. SAFE*1) aims to encourage the environmental monitoring for climate change mitigation and adaptation study and other practical application study using space applications, especially satellite remote sensing technology.

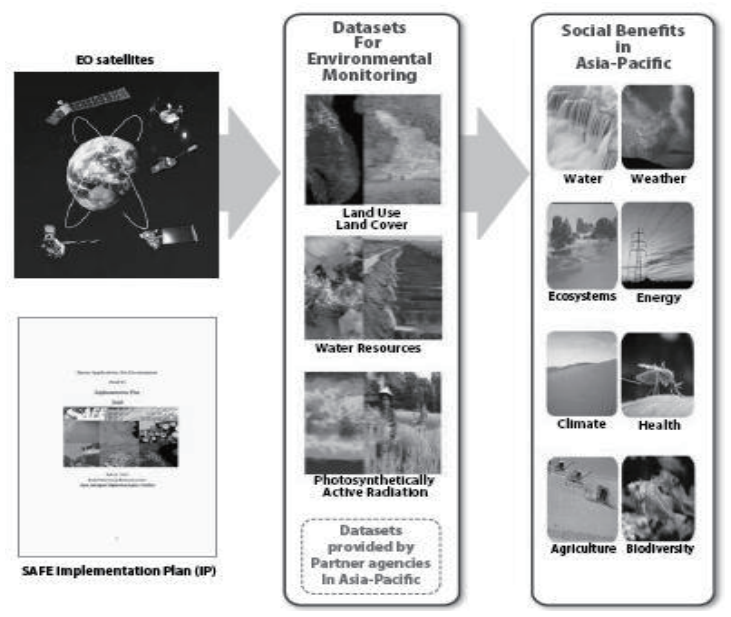

Figure 1. Concept of SAFE activity

\subsection{SAFE Implementation scheme}

SAFE adopted prototyping approach to demonstrate the value of space based technology to tackle climate change issues. SAFE prototype has been implemented by a project team that consists of the prototyping executor, the technical supporter, and the data \& application creator. The team can ask other SAFE members to support their activities, and the members should react to the team's request. To ease barriers to start-up, the first stage of prototype activity is limited to two years. New SAFE prototyping are reviewed by SAFE review board meeting during SAFE workshop every year and SAFE review board members are selected from APRSAF members' researcher with SAFE secretariat by JAXA. Call for proposal is issues about two months before SAFE workshop in advance with template format to propose new SAFE prototyping by APRSAF member country's' entities. Since it is voluntary base activities, each proposed members have to provide necessary resources to analyze earth observation data provided by APRSAF member agencies and applied analyzed results to 
tackle to climate change issues in cooperation with operational governmental bodies (end users). The activities are implemented by a prototyping project team that consists of the end user, the technical supporter, and the data and application creator. The project team members work together under Asian Pacific Regional Space Agency Forum (APRSAF).
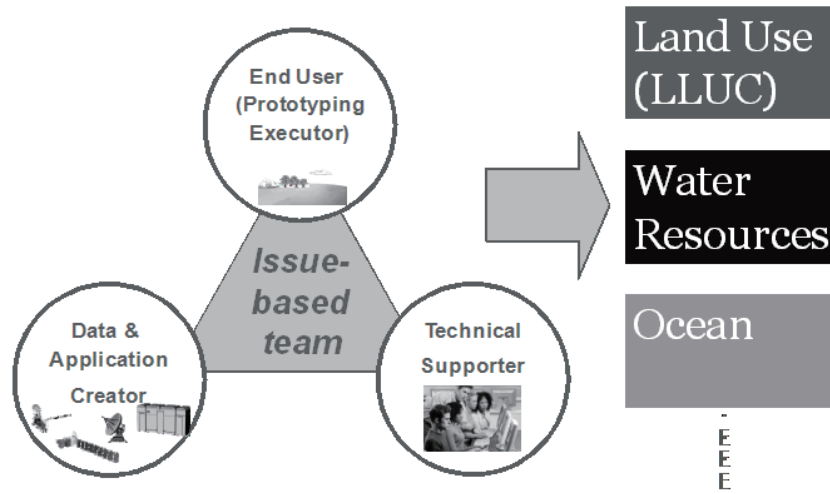

Figure 2. SAFE implementation structure

For Prototyping Executor, they can try to apply the space applications into their routine work related to environmental monitoring. For Technical Supporters / Data \& Applications Creators, they can validate their products/services in actual fields with authority given by the prototyping executor.

SAFE prototyping can provide some of the changing environment parameters in water resources, river water level, land cover, deforestation, agricultural production, and ecosystem and provide a bridge to implement operational and/or practical systems to contribute to solve national/regional climate change adaptation and mitigation issues by using space based technologies in Asia and Pacific region.

\subsection{SAFE prototyping activities}

Through on-going following SAFE prototyping, climate change and other important information by using space based technologies are provided to national/regional end users. SAFE was officially established at APRSAF-15 in Hanoi, 2008 and 1st SAFE WS was held at Pattaya, Thailand (May 2009). In that WS, 7 proposals from 4 countries as new SAFE activities were submitted and two proposals were approved. Mini WS was held at Jakarta, Indonesia (August 2009) and 5 revised proposals were reviewed, of which 2 were endorsed. Then, those two proposals were approved at APRSAF-16 in Bangkok, 2010. Table 1 shows the current SAFE prototype activities.
Table 1. SAFE prototype activities SAFE prototype activities (As of March 2010)

\begin{tabular}{|c|c|c|}
\hline Status & Country & Theme \\
\hline \multirow{4}{*}{ In Action } & Vietnam & Forest monitoring \\
\cline { 2 - 3 } & Vietnam & Integrated water resource management \\
\cline { 2 - 3 } & Cambodia & Water cycle \& agriculture \\
\cline { 2 - 3 } & Laos & Forest monitoring \\
\hline & Sri Lanka & Risk of sea level rise \\
\cline { 2 - 3 } & Indonesia & Potential drought monitoring \\
\hline \multirow{4}{*}{ Proposed } & Indonesia & Coastal zone monitoring \\
\cline { 2 - 3 } & Indonesia & Ocean carbon flux \\
\cline { 2 - 3 } & Sri Lanka & Environmental assessment due to flood \\
\hline
\end{tabular}

\section{ACCOMPLISHMENT}

\subsection{Success story}

There are two success stories in SAFE prototyping in Viet num for forest monitoring and water resources managements from 2008 to 2010 .

\subsection{Forest management}

Vietnamese Forest Protection Department, Ministry of Agriculture and Rural Development (FPD/MARD) is the agency having responsible for Forest Management in Vietnam. FPD has MODIS receiving station and provides wild fire Hotspots information to the rural branch. As the next step, FPD is trying to strengthen the forest management by using of MODIS. Ministry of Agriculture and Rural Development (MARD), Ministry of Natural Resources and Environment (MONRE), Vietnamese Academy of Science and Technology (VAST), Japan Aerospace Exploration Agency (JAXA), University of Tokyo (UT) and Asian Institute of Technology (AIT) are jointly implemented this prototyping.

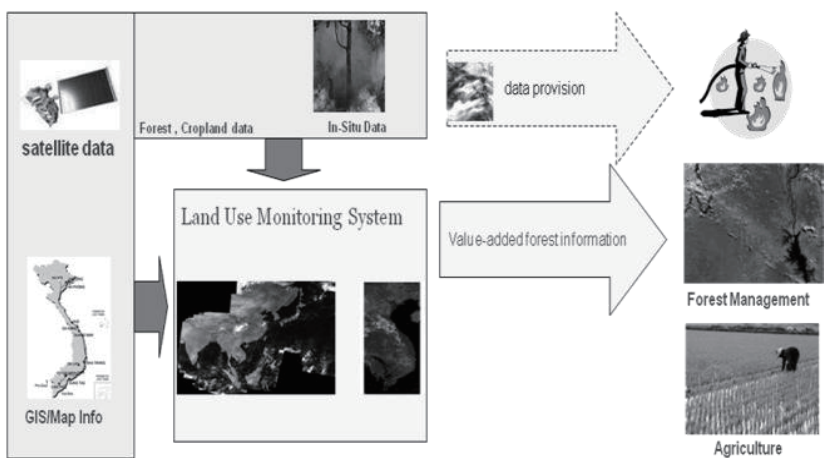

Figure 3 System concept for forest management / land use monitoring

\subsection{Integrated water resource management}

Vietnamese National HYDORO-METEOLOGICAL Service, Ministry of Natural Resources and Environment (NHMS/MONRE) is the agency having responsible for flood management and Metrological Service in Vietnam. NHMS is trying to strengthen the precipitation monitoring by using GsMAP (Global Satellite Mapping of 
Precipitation*2) and ground observation data and reservoirs management under the Asian Water Cycle Initiative in cooperation with Univ. of Tokyo and JAXA.

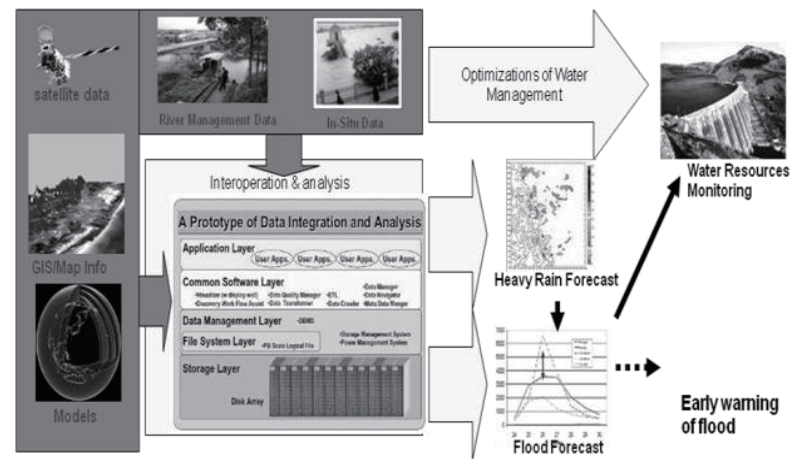

Figure 4. System concept of integrated water resource management

\section{CONCLUSION}

SAFE prototyping is ongoing activity to provide a bridge between earth observation satellite data providers and end users in cooperation with technical supporters. Through showing success story, SAFE prototyping will be provided a corner stone to contribute climate change adaptation and mitigation strategy development and research in Asia Pacific region by using space based technology.

\section{REFERENCE}

1) http://www.eorc.jaxa.jp/SAFE/index.html

2) http://sharaku.eorc.jaxa.jp/GSMaP_crest/index_j.html 